\title{
Experimental and Computational Approaches for the Structural Study of Novel Ca-Rich Zeolites from Incense Stick Ash and Their Application for Wastewater Treatment
}

\author{
Virendra Kumar Yadav $\mathbb{D}^{1},{ }^{1}$ Nisha Choudhary ${ }^{D},{ }^{2}$ Daoud Ali, ${ }^{3}$ G. Gnanamoorthy, ${ }^{4}$ \\ Gajendra Kumar Inwati $\mathbb{D}^{5}$ Mohammed HA. Almarzoug $\mathbb{D}^{3},{ }^{3}$ Gokhlesh Kumar, ${ }^{6}$ \\ Samreen Heena Khan $\mathbb{D}^{2},{ }^{2}$ and Mitesh B. Solanki ${ }^{7}$ \\ ${ }^{1}$ Department of Microbiology, School of Sciences, P P Savani University, Surat, 394125 Gujarat, India \\ ${ }^{2}$ Research and Development Centre, YNC Envis Pvt. Ltd., New Delhi, 110059 Delhi, India \\ ${ }^{3}$ Department of Zoology, College of Science, King Saud University, P.O. Box 2455 Riyadh 11451, Saudi Arabia \\ ${ }^{4}$ Department of Inorganic Chemistry, University of Madras, Guindy Campus, Chennai 600025, India \\ ${ }^{5}$ Department of Chemistry, H.V.H.P. Institute of Post Graduate Studies and Research, S. V. Campus, \\ Sarva Vishwavidyalaya University, Kadi, Gujarat 382715, India \\ ${ }^{6}$ Clinical Division of Fish Medicine, University of Veterinary Medicine Vienna, 1210 Vienna, Austria \\ ${ }^{7}$ Step-Up Jewels PVT. LTD. Khatodara Gate, Surat, 395002 Gujarat, India \\ Correspondence should be addressed to Virendra Kumar Yadav; yadava94@gmail.com
}

Received 16 August 2021; Accepted 19 October 2021; Published 20 November 2021

Academic Editor: Ming Hua

Copyright ( 2021 Virendra Kumar Yadav et al. This is an open access article distributed under the Creative Commons Attribution License, which permits unrestricted use, distribution, and reproduction in any medium, provided the original work is properly cited.

At present, chemical $\mathrm{Si} / \mathrm{Al}$ sources are mainly used as precursor materials for the manufacturing of zeolites. Such precursor materials are quite expensive for commercial synthesis. Here, we have reported the synthesis of Ca-based zeolite from incense stick ash waste by the alkali-treatment method for the first time. Incense stick ash (ISA) was used as a precursor material for the synthesis of low Si zeolites by the alkali-treatment method. The as-synthesized zeolites were characterized by various instruments like particle size analyzer (PSA), Fourier transform infrared (FTIR), X-ray diffraction (XRD), field emission scanning electron microscope (FESEM), electron diffraction spectroscopy (EDS), transmission electron microscopy (TEM), and $\mathrm{X}$-ray fluorescence (XRF). FTIR and XRD helped in the identification of the microstructure and crystalline nature of the zeolites and also confirmed the synthesis of Ca-based zeolite with two thetas at $25.7^{\circ}$. The microscopic analysis by FESEM and TEM exhibited that the size of synthesized Ca-rich zeolites varies from 200 to $700 \mathrm{~nm}$ and they are aggregated and cuboidal in shape. Additionally, structural, electronic, and density of states' characteristics of gismondine $\left(\mathrm{Ca}_{2} \mathrm{Al}_{4} \mathrm{Si}_{4} \mathrm{O}_{16}{ }_{9} \mathrm{H}_{2} \mathrm{O}\right)$ structures were evaluated by computational simulations (first principle, density functional theorem). The structural optimization of structures was carried out in the first stage under the lowest condition of total energy and forces acting on atoms for the lattice constant, as well as the available experimental and theoretical findings. The present research approach predicted the transformation of ISA waste into a value-added mineral, i.e., zeolite, which was further used for the removal of both heavy metals and alkali metals from fly ash-based wastewater using inductively coupled plasma-optical emission spectroscopy (ICP-OES).

\section{Introduction}

Zeolites are crystalline aluminosilicates having elements either from group I or II as counter ions [1]. Zeolites mainly consist of $\mathrm{Al}, \mathrm{Si}$, and $\mathrm{O}$, which forms their basic framework [2]. The structure of zeolites comprises the framework of $\left[\mathrm{SiO}_{4}\right]^{{ }^{4}}$ and $\left[\mathrm{AlO}_{4}\right]^{5}$ tetrahedra linked to each other at the corners by sharing their oxygen $[3,4]$. The tetrahedral 3D network of zeolites has a lot of voids and spaces in them [5], and these voids supplement the characteristics to the zeolites, for instance, the adsorption of molecules in the huge internal channels $[6,7]$. Zeolites can be readily dehydrated and 
rehydrated [8] and are used as cation exchangers [9], soil decontamination $[9,10]$, and molecular sieves [11]. The unique and remarkable properties of zeolites viz. porous nature, negative charge, water-insoluble, higher melting point, and water trapping property [12-14] make them a potential material as an adsorbent [15] for wastewater treatment [16], as fertilizers in agriculture [17], and as an ion exchanger [18-26]. Based on their origin, zeolites can be of two types, i.e., natural or synthetic $[27,28]$. Synthetic zeolites are synthesized in laboratory conditions by optimizing the conditions.

Presently, for commercial production, synthetic zeolites are preferred over natural zeolites, as they can be modified as per the need of the industry. Moreover, synthetic zeolites are more precise, ordered, crystalline, and uniform in size of the particles. However, the synthesis of zeolites from Al- and Si-rich chemical sources is not economical [29]. On the other hand, natural zeolites are present in nature in the form of volcanic ashes [30,31], sedimentary rocks [32], clay and kaolins [33, 34], fly ash [28, 35], bauxite minerals [36], and other earthy materials which may reduce the cost of the zeolites but purity remains a major concern. Incense stick ash (ISA) being a waste material of household and religious places can act as a source of zeolites owing to its similar composition to the natural zeolites $[37,38]$. Yet to date, no attempt has been made by the scientific community for the synthesis of zeolites from overlooked waste like ISA [39]. Every day, tons of incense sticks are consumed at religious places and homes in countries like China, Thailand, Japan, Burma, and India for deity purposes which in turn produces ISA. The burning of incense stick leaves behind ashes as a residue that has to be disposed of in the river or other water sources especially in India where it holds religious values and is considered holy [40,41]. Indian incense stick ash has high $\mathrm{Ca}, \mathrm{Mg}, \mathrm{Fe}, \mathrm{Si}$, and $\mathrm{Al}$ content where $\mathrm{Ca}$ and $\mathrm{Mg}$ alone constitute $50-60 \%$ total weight of the ash [42-44], while silica is $20 \%$ and alumina is $5-10 \%$ forming $25-30 \%$ of the total weight. All these elements are essential for the synthesis of zeolites [35]. So, instead of disposing the ashes into the river, it can be utilized for the synthesis of zeolites which may have potential to treat wastewater and protect the environment.

ISA was employed in the synthesis of zeolites, by the alkali-treatment method under laboratory conditions. As per our knowledge, ISA-based synthesis of zeolites has been reported for the first time over here. The synthesized zeolites were characterized by particle size analyzer (PSA), Fourier transform infrared (FTIR), field emission scanning electron microscope (FESEM), electron diffraction spectroscopy (EDS), transmission electron microscopy (TEM), X-ray diffraction (XRD), and X-ray fluorescence (XRF). The synthesized zeolites belong to the sodalite class and are crystalline, aggregated, and cuboidal in shape with size ranging from $200 \mathrm{~nm}$ to $700 \mathrm{~nm}$. Further, the potential of synthesized zeolites was explored for the removal of heavy metals and alkali metals from fly ash aqueous solutions with respect to time using inductively coupled plasma-optical emission spectroscopy (ICP-OES) analysis. In conclusion, the utilization of ISA for zeolites will reduce the disposal problem of ISA and water pollution.

\section{Materials and Methods}

2.1. Materials. Incense stick ash, Conc. $\mathrm{HCl}$ (RENKEM), Conc. $\mathrm{H}_{2} \mathrm{SO}_{4}$ (RENKEM), $\mathrm{NaOH}$ (SRL), ethanol (SRL, India), round bottom flasks, $100 \mathrm{ml}$ beakers, Whatman filter paper no. 42 (Axiva, India), and reflux condenser were used.

2.2. Method. The incense stick ash was transferred in a $100 \mathrm{ml}$ beaker and washed 2-3 times with distilled water to eliminate the carbon and other unburnt particles. Further, from the ISA slurry, ferrous fractions were extracted using an external neodymium magnet [44]. Removal of ferrous from ash enhances the zeolitic property as it interferes with the transformation of zeolites [45]. The nonferrous fractions were dried either at room temperature or in an oven at $60^{\circ} \mathrm{C}$ till complete dryness. Thereafter, the nonferrous part was treated with $2 \mathrm{~N} \mathrm{H}_{2} \mathrm{SO}_{4}$ in a round-bottomed (RB) flask in solid to liquid ratio of $1: 10$ at room temperature (RT). The mixture was continuously stirred using a magnetic stirrer under reflux. It removes the excess of Ca in the form of chlorides from the ash. The residue was collected by centrifuging the mixture at $7000 \mathrm{rpm}$ for 5 minutes and discarding the supernatant.

The dried residue was further treated with $2 \mathrm{~N}-6 \mathrm{~N}$ $\mathrm{H}_{2} \mathrm{SO}_{4}$ at $95^{\circ} \mathrm{C}$ under stirring in a reflux condenser which removes $\mathrm{Al}$ from the ash by dissolving it at higher temperature. Further, the residue was collected by centrifuging the mixture at $7000 \mathrm{rpm}$ for 5 minutes. The supernatant was removed, and the residue was washed 2-3 times with distilled water to eliminate any acidic moieties.

Further, in a RB flask, the dried residue was treated with $4-8 \mathrm{M} \mathrm{NaOH}$ in a ratio of $1: 5$ at $95^{\circ} \mathrm{C}$ along with continuous stirring for 90 minutes under reflux. The residue was collected by centrifuging the mixture at $7000 \mathrm{rpm}$ for 10 minutes. The residue was collected, and the supernatant was discarded. The final residue was washed 2-3 times using distilled water to eliminate any $\mathrm{NaOH}$ or $\mathrm{NaCl}$ particles from the surface and dried in a hot air oven at $60^{\circ} \mathrm{C}$. The complete schematic process for synthesis of zeolites from ISA is shown in Figure 1.

2.2.1. Preparation of 20\% Fly Ash Aqueous Solutions. 50gram fly ash was weighed and mixed with the $250 \mathrm{ml}$ distilled water in a plastic bottle, and the mixture was placed inside a horizontal shaker at $200 \mathrm{rpm}$ for $24-48$ hours. After the time interval, the mixture was allowed to settle down at RT and filtered using Whatman filter paper no. 42 where the aqueous solution was retained while the residue was discarded. The aqueous solution was stored in a glass bottle which was used as a source of heavy and alkali metals.

2.2.2. Batch Adsorption Study of Heavy and Alkali Metals from CFA Aqueous Solutions. Batch adsorption study was conducted for the remediation of heavy and alkali metals from aqueous solutions of fly ash using ISA synthesized zeolites. For this, $150 \mathrm{ml}$ of CFA aqueous solution was transferred in a $250 \mathrm{ml}$ Erlenmeyer flask. To this aqueous solution, $9 \mathrm{mg}$ synthesized zeolites were added. The mixture was kept in an incubator shaker at $150 \mathrm{rpm}$ and $25^{\circ} \mathrm{C}$. An aliquot of the sample was collected initially at time 0 minute 


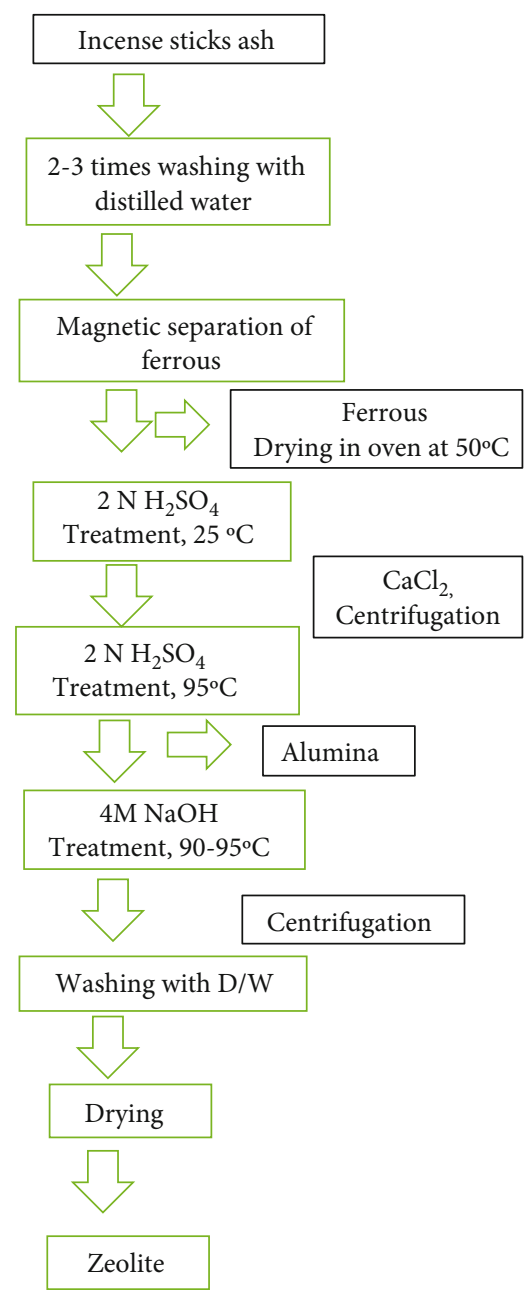

FIGURE 1: Schematic flowchart for zeolite synthesis from ISA.

while the final sample was collected after 120 minutes. Both the samples were analyzed by the ICP-OES for the detection of the concentration of various heavy and alkali metals after the specified time.

2.3. Characterization of Ca-Rich Zeolites. X-ray fluorescence spectroscopy (XRF) was used for the analysis of major elemental oxides of Ca-rich zeolites. The analysis was done to detect the chemical content of the zeolite sample, and for that, 5 grams of Ca-rich zeolite powder sample was taken and measured with PANalytical Epsilon 5, The Netherlands, fitted with a $4 \mathrm{KW}$ with $60 \mathrm{kV}, 125 \mathrm{~mA}$, Rh anode X-ray tube. FTIR analysis was carried out using PerkinElmer, "Spectrum 6500" (USA) by solidifying the samples with $\mathrm{KBr}$ pellets at a resolution of $2 \mathrm{~cm}^{-1}$. The mid-IR region, i.e., from $400-4000 \mathrm{~cm}^{-1}$, provided the transmission measurement. The particle size measurement and distribution of the ISA sample were analyzed by Malvern Zetasizer, Z90 (UK), particle size analyzer with a detection range of $0.1 \mathrm{~nm}$ to 300 microns, and it was analyzed by three average runs. The FESEM-EDS helps in revealing the size and eternal features, porosity, and shape of the synthesized calcium-rich zeolites. The surface structural analysis of zeo- lites was analyzed by the FESEM, Nova, NANOSEM 450 (FEI, USA), besides trace and minor elements by the EDS analysis using Oxford elemental analyzer attached with it. The XRD patterns of the calcium-rich zeolites were obtained using a D-8 Advance, Bruker (Germany), instrument that analyzed the sample in powdered form to confirm the nature and class of the synthesized zeolites. The XRD patterns were recorded in the 2-theta range of 5-70, with a step size of 0.02 and a time of 2 seconds/step at $30 \mathrm{kV}$ and a current of $30 \mathrm{~mA}$. The HRTEM was used for the identification of morphological details of zeolites, d-spacing, and diffraction pattern. The zeolite was dispersed into the double-distilled water and sonicated for 10 minutes, and using the drop cast method, a thin layer was deposited on carbon-coated copper grids which were analyzed by FEI Model Tecnai G2 20 Twin $(200 \mathrm{kV})(\mathrm{USA})$.

\section{Results and Discussion}

The basic chemical composition of ISA comprises oxides such as $\mathrm{CaO}$ (49.6\%), $\mathrm{SiO}_{2}$ (20.3\%), $\mathrm{Al}_{2} \mathrm{O}_{3}$ (4.7\%), $\mathrm{Fe}_{2} \mathrm{O}_{3}$ (4.28\%), $\mathrm{MgO}(3.9 \%)$, and $\mathrm{K}_{2} \mathrm{O}(8.2 \%)$, making it a suitable material for the synthesis of the zeolite [44]. The Si/Al ratio of ISA was four which indicates a higher amount of silica in the ISA. Through alkali activation and simultaneous heating, the silica phase (15-20\%) existing in ISA participates in the zeolitization process by dissolving into the solution whereas quartz or mullite remains in the nonreactive mineral phase [46]. Materials with higher Ca content form calcium hydroxide in aqueous media, and owing to its lower water solubility, Ca forms calcium carbonate during zeolitization [46]. During this step, there is a rise in the $\mathrm{pH}$ of the solution, due to calcium hydroxide along with $\mathrm{NaOH}$; moreover, $\mathrm{Ca}$ substitutes the native $\mathrm{Na}^{+}$ions in the sodium zeolites with $\mathrm{Ca}^{2+}$ ions; hence, it may generate some calcium-exchanged zeolites $[46,47]$. The ISA treatment with the $\mathrm{NaOH}$ hydrothermal method synthesizes zeolites by the following mechanism or chemical reactions:

$$
\text { ISA }+x \text { mold } m^{-3} \mathrm{NaOH} \underset{\text { Time }, \Delta}{\longrightarrow} \text { Zeolite }+ \text { Residum }
$$

\subsection{FTIR for Identification of Functional Groups of Zeolites.} FTIR spectroscopy is an important analytical technique that is used for the identification of the functional groups present in the synthesized zeolites. On the basis of functional group, a zeolite can be classified into its specific class along with XRD and EDS data. Figure 2 shows a typical FTIR spectrum of ISA-based Ca-rich zeolite products like calcium carbonate which shows polymorphism [48]. The bands around $460 \mathrm{~cm}^{-1}$ are attributed to the interstitial pore formation in the synthesized zeolites [49-52]. The bands around $1135 \mathrm{~cm}^{-1}$ are ascribed to the silicate bond Si-O-Si $[53,54]$, while sharper and deeper nature of the bands indicates enhanced crystallinity of the synthesized zeolites [55]. The bands near $1600 \mathrm{~cm}^{-1}$ are due to the $-\mathrm{OH}$ molecule, and another band near $3435 \mathrm{~cm}^{-1}$ is because of the bending vibration of the water molecule in the samples [56]. Incidentally, broader transmittance bands are detected between 3450 and 


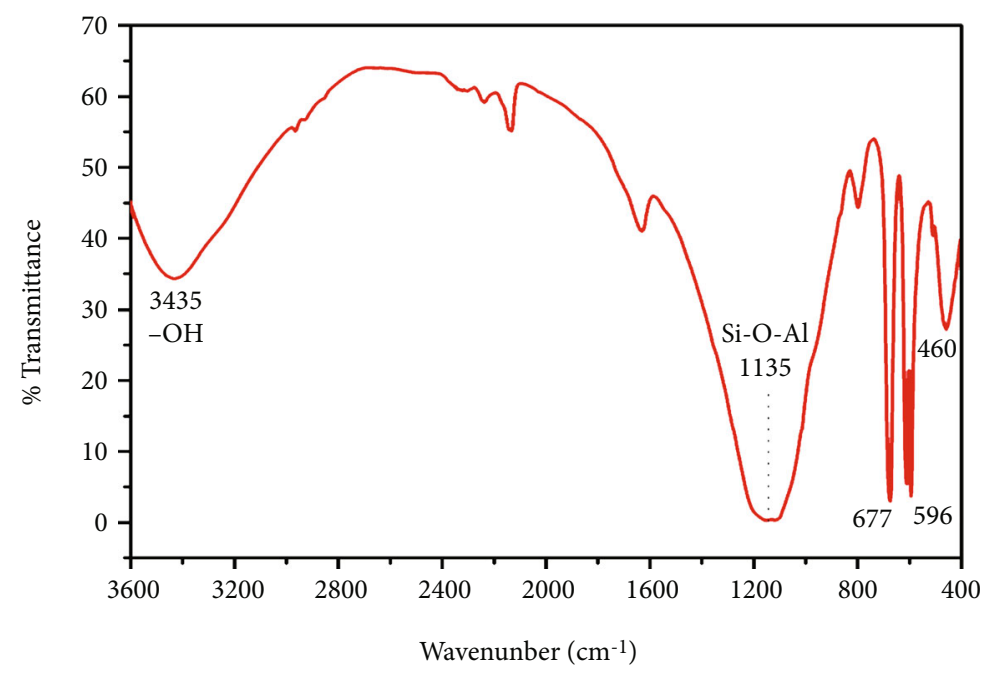

FIGURE 2: FTIR spectra of calcium-rich zeolite particles.

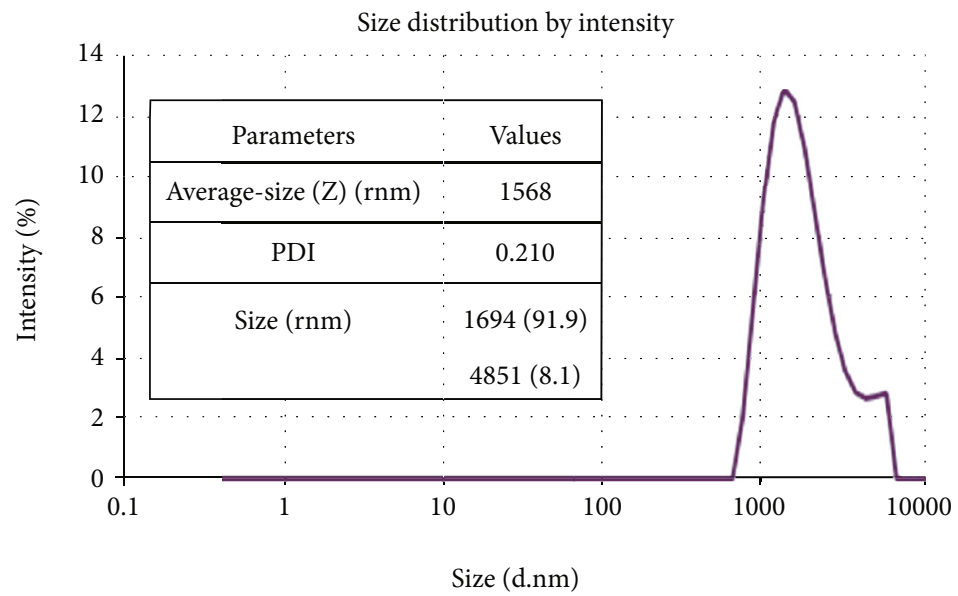

Figure 3: Particle size distribution of calcium zeolite particles.

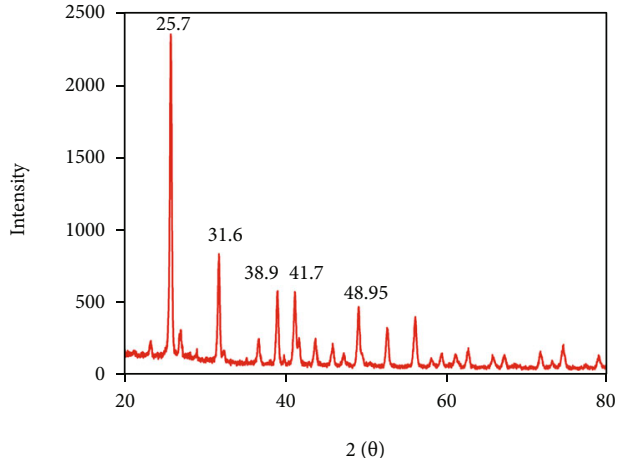

FIgURE 4: XRD diffractogram of calcium-rich zeolite particles.

$3440 \mathrm{~cm}^{-1}$ and centered at $3435 \mathrm{~cm}^{-1}$ which can be assigned to an asymmetrical O-H- stretching linked to $\mathrm{Na}^{+}, \mathrm{Ca}^{2+}, \mathrm{Si}^{4+}$, and/or $\mathrm{Al}^{3+}$ [57].

This indicates that there is bridging between $\mathrm{Si}$ and $\mathrm{Al}$ tetrahedra by the $-\mathrm{OH}$ ion. However, hydrated aluminum silicates comprised of such $\mathrm{OH}$ - bonding in the end products also exist. The stretching vibrations near $3450 \mathrm{~cm}^{-1}$ and bending vibrations at $1640-1620 \mathrm{~cm}^{-1}$ in the end products suggest zeolite crystallization and higher cation exchange capacity (CEC) [58].

3.2. PSA for the Particle Size Distribution of Zeolites. Figure 3 shows the particle size distribution of calcium zeolite particles. The average particle size is $1568 \mathrm{~nm}$ while the graph displays two peaks, a major peak at $1694 \mathrm{~nm}$ and a minor peak near $4851 \mathrm{~nm}$. The PSA shows a larger particle size as compared to the TEM $(200-700 \mathrm{~nm})$ due to the fact that in PSA there is a formation of hydrodynamic layer (includes core and molecules adsorbed over the surface) around the nanoparticle which gives overall larger particle size [59]. Moreover, TEM analysis requires a dry sample; however, PSA uses a sample in a solvated state where solvent molecules associate with the nanoparticle surface to form a hydration layer [60], while calculating the particle size using TEM, this hydration layer is absent over the nanoparticle surface; hence, the obtained particle size was comparatively 


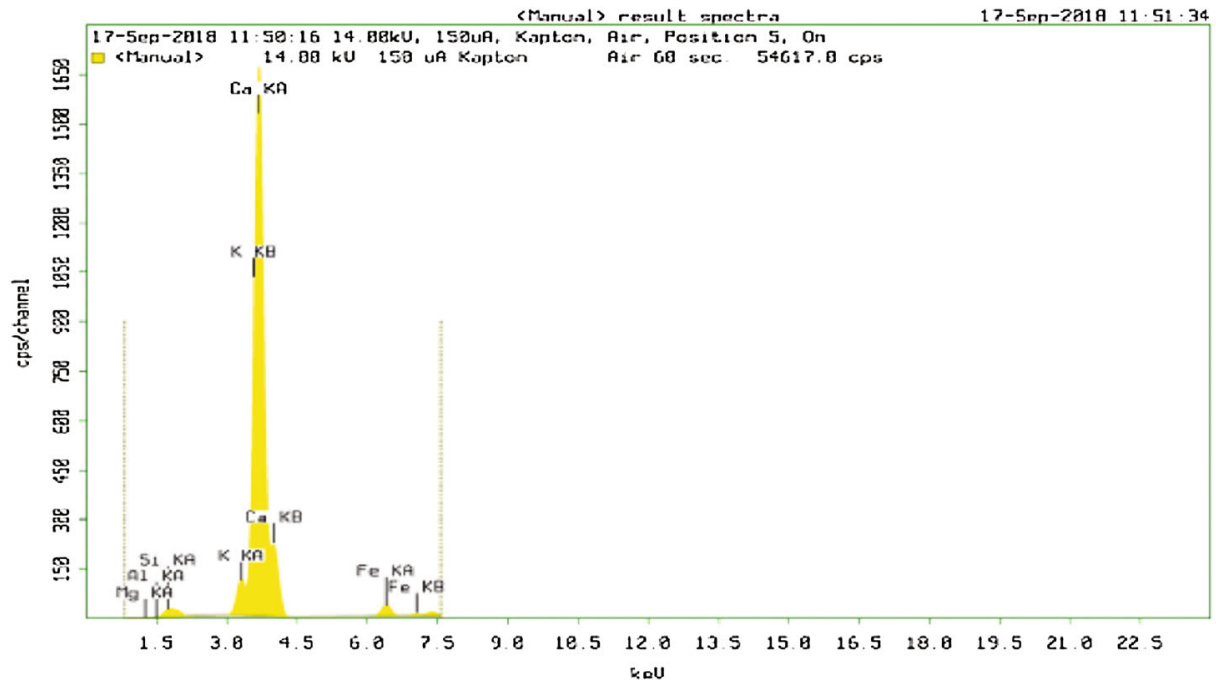

FIGURE 5: XRF spectra of Ca-rich zeolites.

TABLE 1: Major chemical components of calcium-rich zeolites by XRF.

\begin{tabular}{lccccc}
\hline $\mathrm{Al}$ & $\mathrm{Si}$ & $\mathrm{Fe}$ & $\mathrm{Ca}$ & $\mathrm{Mg}$ & $\mathrm{K}$ \\
\hline 9.684 & 586.197 & 888.618 & 44060.21 & 10.112 & 2826.267 \\
\hline
\end{tabular}

lower [61]. The PDI of the particle is 0.210 which proves that the particles are monodispersed in the solvent.

\subsection{XRD for Phase Identification and Confirmation of Zeolite} Synthesis. The XRD diffractogram in Figure 4 revealed the minerals and crystalline nature of the Ca-zeolite which shows a major intensity peak at $25^{\circ}$ and several minor intensity peaks at $31.6,38.9,41.7$, and $48.95^{\circ}$. The formation of zeolites was determined based on the peak at $25^{\circ}$ and $\mathrm{d}$-spacing values. The most common Ca-based zeolites are gismondine $\left(\mathrm{Ca}_{2} \mathrm{Al}_{4} \mathrm{Si}_{4} \mathrm{O}_{16} \cdot 9 \mathrm{H}_{2} \mathrm{O}\right)$ which have the characteristic peaks at $21.7^{\circ}, 26.6^{\circ}$, and $27.9^{\circ}$ and the peak at $32.6^{\circ}$ could be due to calcite [62].

3.4. XRF Analysis of Zeolites for Chemical Composition of Zeolites. XRF technique is the most reliable technique for the detection of major elemental oxides present in a sample. Figure 5 shows a typical XRF spectrum of an ISA-based zeolite material, whose elemental composition is provided in Table 1 . The spectra clearly show that the zeolite has the highest amount of $\mathrm{Ca}$, followed by potassium, Fe, Silica, $\mathrm{Mg}$, and $\mathrm{Al}$. Higher $\mathrm{Ca}$ content confirms the presence of Ca-based zeolites. But the lower value of $\mathrm{Al}$ indicates that the zeolite needs to be supplemented with $\mathrm{Al}$ from outsource to maintain the $\mathrm{Si} / \mathrm{Al}$ ratio. Lower $\mathrm{Al}$ content, i.e., 5-8\%, in ISA can be maintained during the zeolitization step [62]. The resultant zeolite is low Si/Al-based zeolites [63]. The Ca-based zeolite nature is also supported by the FTIR and FESEM-EDS.

3.5. Morphological Analysis of ISA and Ca-Rich Zeolites by FESEM-EDS. Figures 6(a) and 6(b) show the FESEM micrographs of incense stick ash which shows irregularly shaped particles displaying higher aggregation. The size of the particles is mainly in microns, i.e., 1-12 microns. The aggregated particles are carbon- and calcium-rich particles which are also evident from XRF. The ISA particles are mainly dominated by the $\mathrm{Ca}$ and carbon particles. The brighter regions are metal-rich regions like $\mathrm{Al}, \mathrm{Si}, \mathrm{Fe}$, and $\mathrm{Ca}$ while the darker rich regions are carbon-rich regions. Figure $6(\mathrm{~g})$ is the EDS spot of the zeolites while Figure 6(h) is the EDS spectra and elemental composition table of the synthesized calcium-rich zeolites from ISA. The EDS spectra are showing mainly $\mathrm{Ca}, \mathrm{O}, \mathrm{C}$, and $\mathrm{S}$ while $\mathrm{Al}$ and $\mathrm{Si}$ are present in a much lesser amount. $\mathrm{Ca}, \mathrm{O}, \mathrm{Si}$, and $\mathrm{Al}$ indicate the formation of Ca-based zeolites mainly gismondine [64]. C and $\mathrm{S}$ are present as impurities which can be attributed due to the improper washing of the zeolite sample. As ISA has high $\mathrm{Ca}$ and $\mathrm{C}$, so the synthesized Ca-based zeolite has both the elements in higher amount.

The absence of ferrous from EDS elemental composition analysis indicates the removal of most of the ferrous particles, which have a positive effect on the property of zeolites [65] since ferrous may interfere with the purity of the zeolites.

3.6. TEM Analysis for Morphology of Synthesized CalciumRich Zeolites. At the time of exposure of zeolites with the electron beams, there is a possibility of damage and charging of zeolites, so there is a requirement of sophisticated techniques such as high-resolution TEM for visualization [66]. The TEM micrographs shown in Figures $7(\mathrm{a})-7(\mathrm{~d})$ reveal the morphology similar to the FESEM, where the cuboidalshaped particles have lengths varying between $200 \mathrm{~nm}$ and $700 \mathrm{~nm}$ and a width ranging from $100 \mathrm{~nm}$ to $300 \mathrm{~nm}$. Besides, there are several aggregations of smaller particles which are visible as brighter particles under the TEM field. The first three images depict Ca-rich zeolite particles in groups, while Figures $7(\mathrm{~d})$ and $7(\mathrm{e})$ show two and single particle, respectively. In both, the image particles are cuboidal in shape, while in Figure 7(e), the dimension of a single 


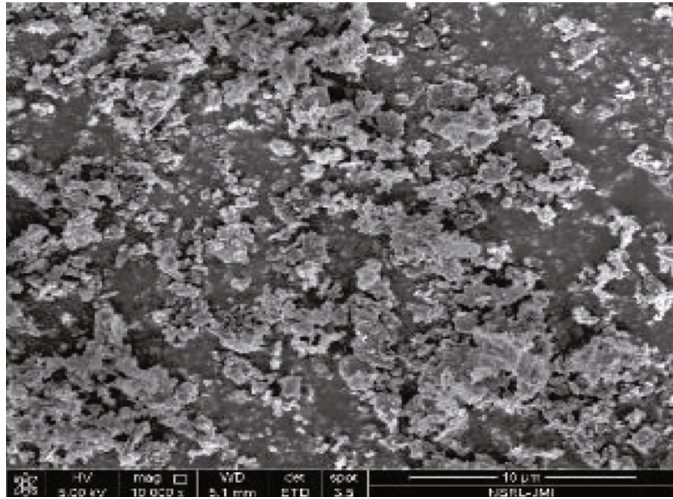

(a)

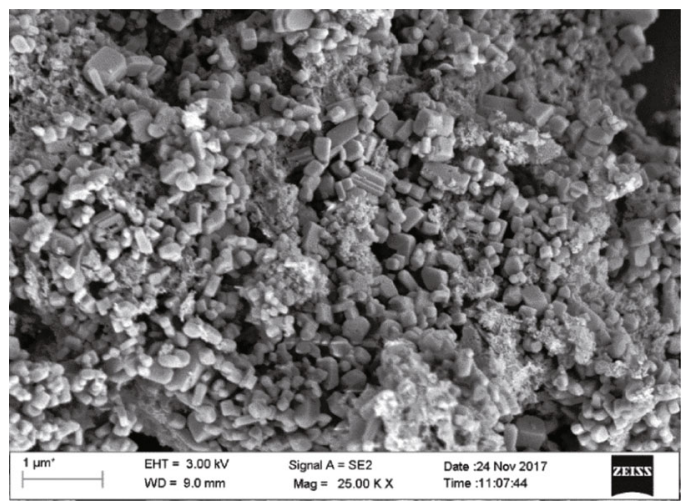

(c)

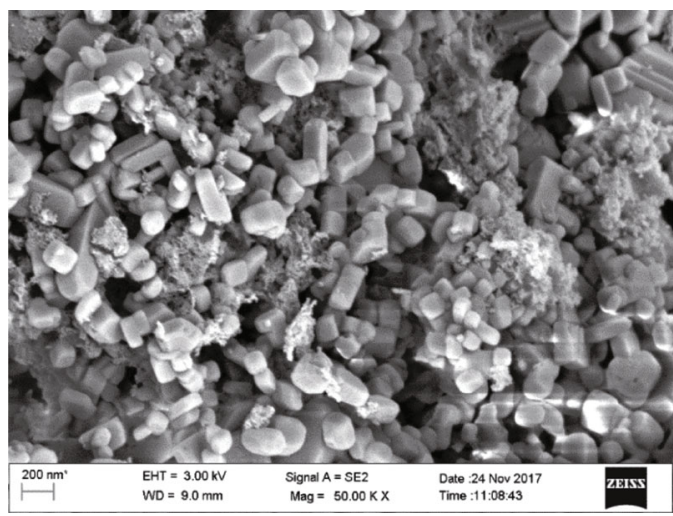

(e)

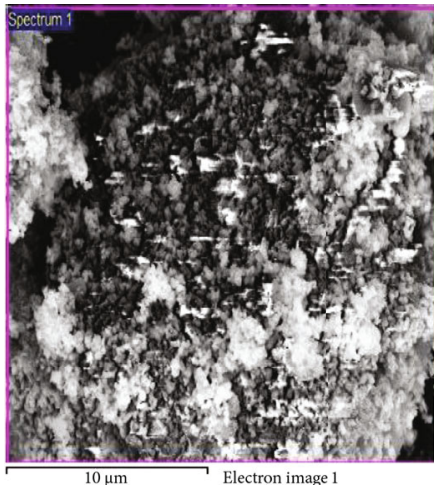

(g)

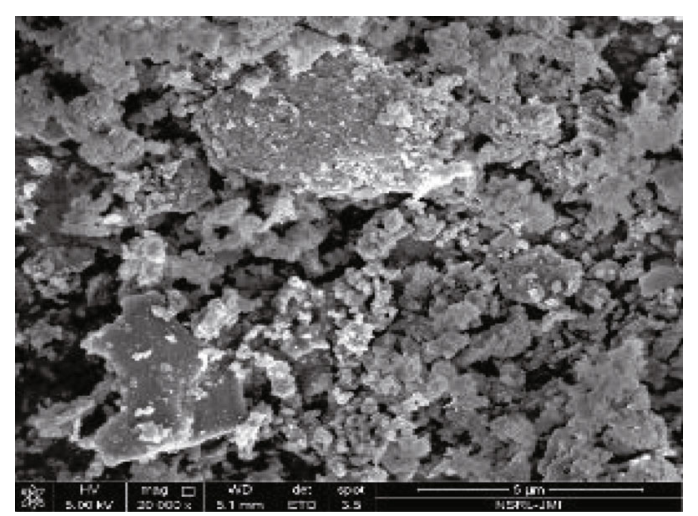

(b)

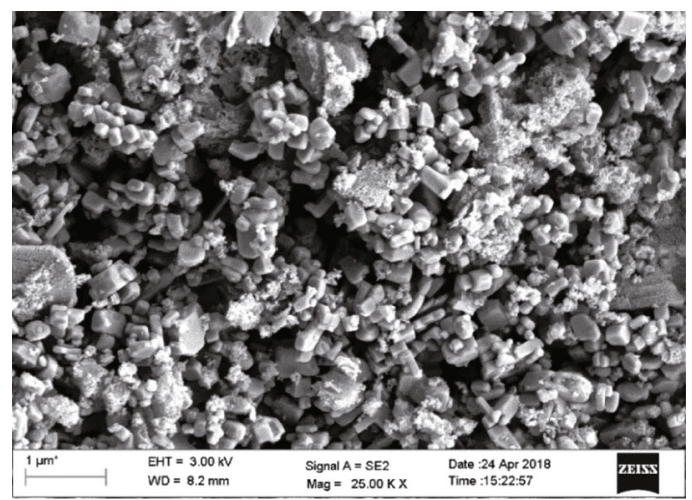

(d)

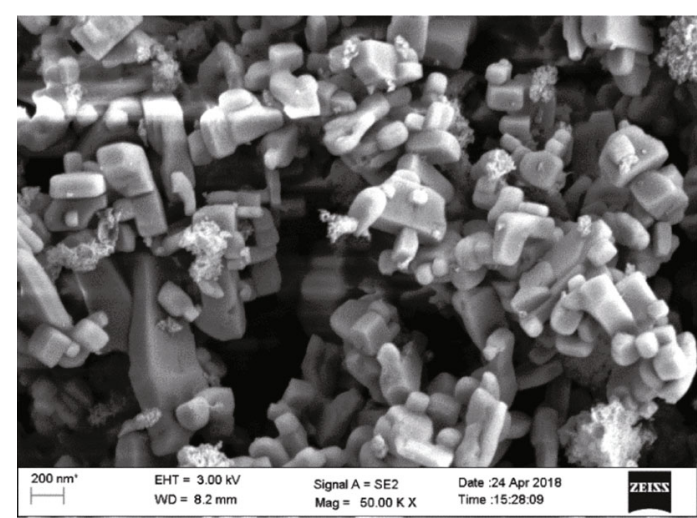

(f)

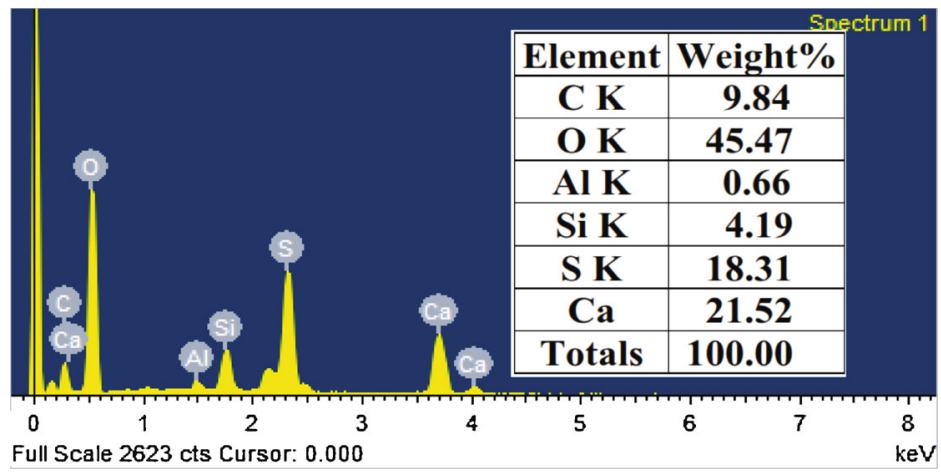

(h)

FIGURE 6: FESEM images of (a,b) incense stick ash, (c-f) calcium-rich zeolites, (g) EDS spot, and (h) EDS spectra. 


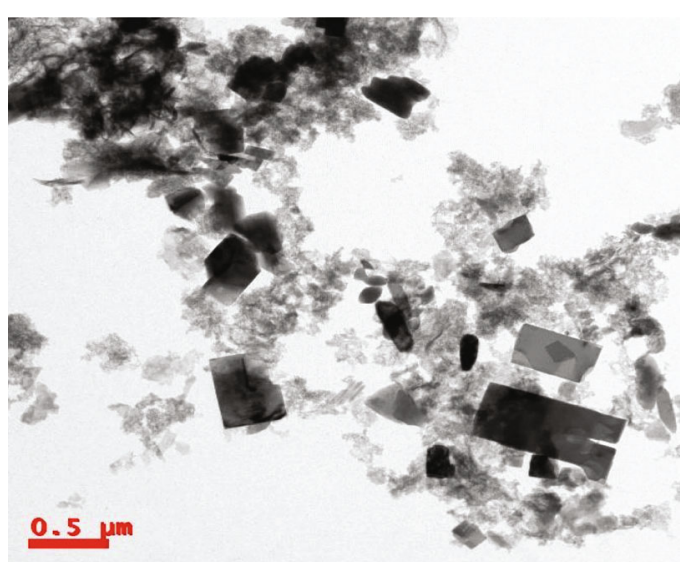

(a)

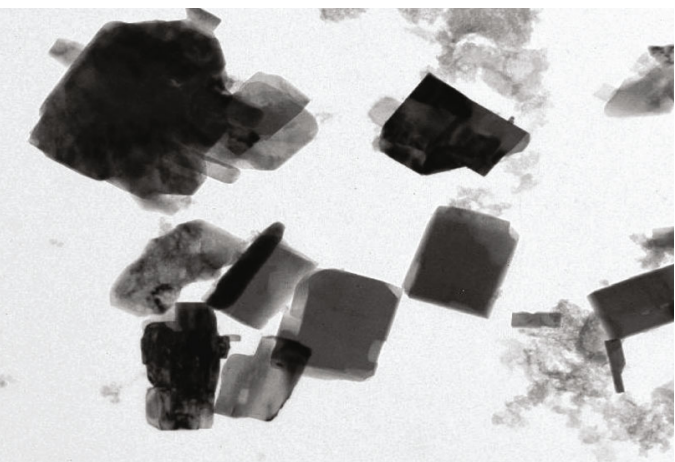

$0.2 \mu \mathrm{m}$

(c)

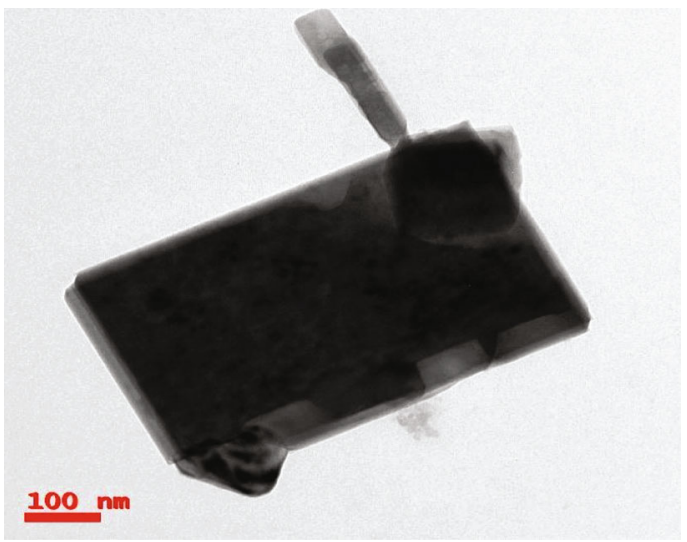

(e)

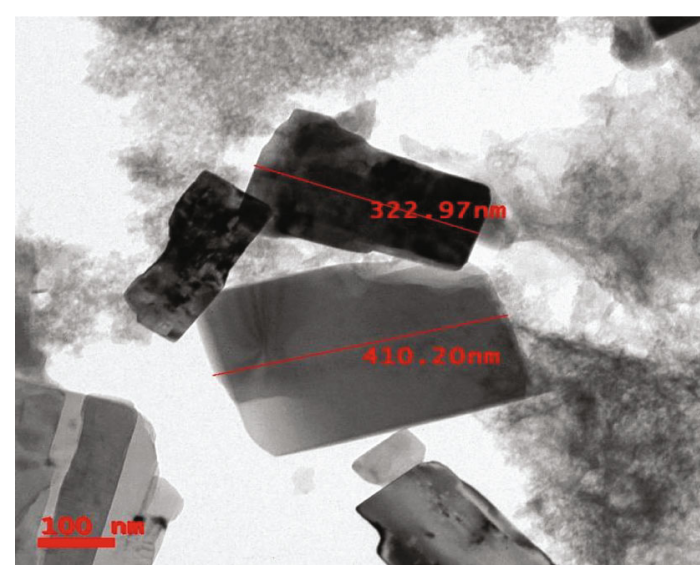

(b)

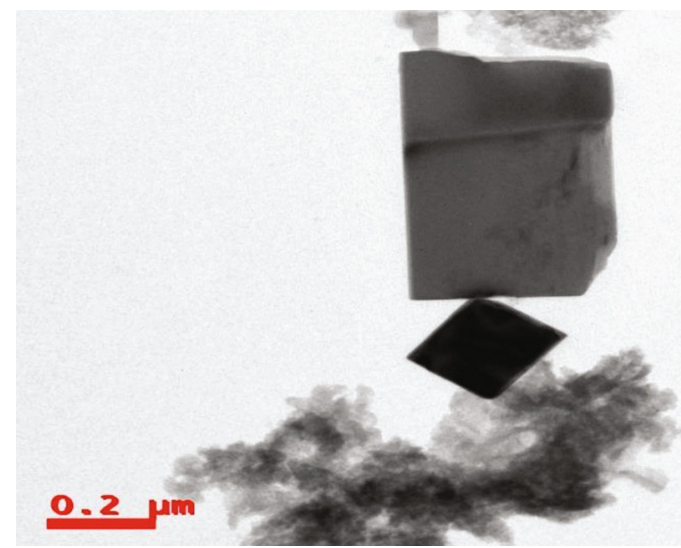

(d)

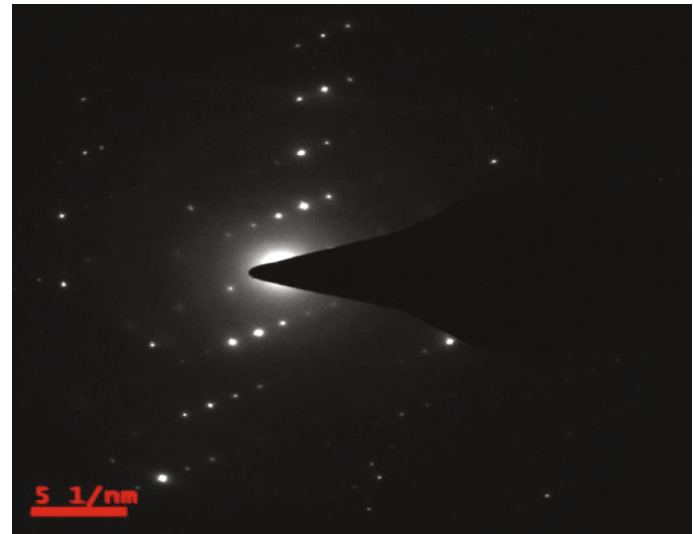

(f)

Figure 7: TEM micrographs of (a-e) calcium-rich zeolites and (f) SAED pattern.

TABLE 2: Heavy metal concentration after different time intervals.

\begin{tabular}{lccccccc}
\hline Time & \multicolumn{8}{c}{ Concentration $(\mathrm{mg} / \mathrm{l})$} \\
Minutes & $\mathrm{Cu}$ & $\mathrm{Cd}$ & $\mathrm{Cr}$ & $\mathrm{Co}$ & $\mathrm{Ni}$ & $\mathrm{Pb}$ & $\mathrm{Zn}$ \\
\hline 0 & 1.340 & 0.092 & 0.15 & 0.293 & 0.833 & 0.014 & 4.49 \\
120 & 0.97 & 0.033 & 0.03 & 0.233 & 0.638 & -0.034 & 2.30 \\
\hline
\end{tabular}

particle is $250 \mathrm{~nm}$ wide and $700 \mathrm{~nm}$ long. The crystal images of zeolite are overlapping to some extent; the edges of the crystal are obvious. Moreover, the scattering area electron diffraction (SAED) pattern in Figure 7(f) shows that the particles have polycrystalline nature.

The Ca-based or Ca-rich zeolites have several advantages over Na-based zeolites. The application of Na-based zeolite is restricted in soil and water and is not an appropriate material to be used in agricultural- and aqua-based products as 
TABLE 3: Concentration of nonheavy metals after different time intervals.

\begin{tabular}{lccccc}
\hline Time & \multicolumn{5}{c}{ Concentration $(\mathrm{mg} / \mathrm{l})$} \\
Minutes & $\mathrm{Ba}$ & $\mathrm{Ca}$ & $\mathrm{Mg}$ & $\mathrm{Mn}$ & $\mathrm{Al}$ \\
\hline 0 & 1.02 & 1.340 & 0.092 & 5.540 & 152.0 \\
120 & 0.27 & 0.97 & 0.033 & 3.74 & 56.9 \\
\hline
\end{tabular}

higher sodium content enhances the salinity and sodicity of the soil/water [67]. The challenging problems in such situations are (a) to reduce the harsh conditions of Na-based ISA zeolites during its application in soil and water and (ii) to increase the Ca-exchanged zeolites. So the synthesized zeolites from the ISA will solve the problem associated with these issues.

3.7. Remediation of Heavy Metals and Alkali Metals by CaRich Zeolites. Here, the dosage of the zeolite particles was fixed, i.e., $10 \mathrm{mg}$ in $200 \mathrm{ml}$ solution of the wastewater. The remediation of heavy $(\mathrm{Cd}, \mathrm{Mn}, \mathrm{Zn}, \mathrm{Pb}, \mathrm{Al}, \mathrm{Cu}, \mathrm{Co}, \mathrm{Cr}$, and $\mathrm{Ni}$ ) and alkali metals ( $\mathrm{Ca}, \mathrm{Mg}, \mathrm{Ba}$, and $\mathrm{Al}$ ) by adsorption process in a multicomponent system was performed by shake flask method in an incubator shaker. The percent removal of heavy metals was calculated by the following formula:

$$
\text { Removal\% }=\left[\left(C_{\mathrm{o}}-C_{\mathrm{f}}\right) C_{\mathrm{o}}\right] \times 100,
$$

where $C_{\mathrm{o}}$ and $C_{\mathrm{f}}$ are the initial and equilibrium concentration (ppm) of metal ions in solution, respectively.

The removal efficiency of all the seven heavy metals $(\mathrm{Cu}, \mathrm{Co}, \mathrm{Ni}, \mathrm{Pb}, \mathrm{Cr}, \mathrm{Zn}$, and $\mathrm{Cd})$ decreased, in the solution after 2 hours as shown in Table 2, while the value of $\mathrm{Pb}$ reached below the detection level of ICP-OES as the $\mathrm{Pb}$ concentration was already less in the wastewater solution in comparison to the other heavy metals. Moreover, higher electronegativity of $\mathrm{Pb}$ can also be a contributing factor [68]. In the process of metal ion adsorption, the elemental property of electronegativity becomes highly significant as higher electronegativity is responsible for the stronger covalent formation of metals with $\mathrm{O}$ atoms situated on the surface of zeolites [69].

As far as the remediation of the nonheavy metals $(\mathrm{Ba}$, $\mathrm{Ca}, \mathrm{Mg}, \mathrm{Mn}$, and $\mathrm{Al}$ ) is concerned, a reduction in the value of $\mathrm{Ba}, \mathrm{Ca}, \mathrm{Mg}, \mathrm{Mn}$, and $\mathrm{Al}$ was noticed after 2 hours as shown in Table 3. All these are alkali metals that are present significantly in fly ash, and their disposal into the river or other water bodies will increase the alkalinity or hardness of water [70]. So zeolites can be an efficient and economical adsorbent for the removal of alkali metals from wastewater [70]. Here, the adsorption of both heavy metals and alkali metals takes place on the surface of zeolite particles due to the electrostatic attraction and coordination. Several investigators have also reported the remediation of numerous heavy metals from wastewater by nanoadsorbents due to electrostatic attraction and coordination [71]. The zeolite surface is positively charged at neutral or slightly acidic $\mathrm{pH}$, which gives rise to PZC repulsion to cations. The coor- dination between $\mathrm{CH}$ on the zeolite surface and the bivalent metal ions is responsible for the adsorption of cations on the zeolites. Such phenomenon of adsorption and deposition was observed because the fly ash aqueous solutions are a multicomponent system where several heavy metals and nonheavy metals compete for the limited adsorption sites. Once these binding sites are occupied, there is a healthy competition among ions and nonmetallic ions, which results in desorption of the heavy metals.

\section{Computation Approach}

A theoretical simulation to investigate the structural, electronic, and density of states' characteristics of gismondine $\left(\mathrm{Ca}_{2} \mathrm{Al}_{4} \mathrm{Si}_{4} \mathrm{O}_{16} \cdot 9 \mathrm{H}_{2} \mathrm{O}\right)$ structures was carried out. Figure 8 shows the estimated theoretical models using first principles, density functional theory calculations [72] as implemented in the Quantum Espresso program [73]. Interaction of atomic cores and valence electrons utilizing the extremely soft pseudopotential technique is proposed by Vanderbil [73]. Perdew-Burke-Ernzerhof (PBE) [74] exchange correlational functional was used to solve the Kohn-Sham equation [75], using the generalized gradient approximation [76]. It has shown its ability to replicate ground state energy characteristics across a broad range of a variety of crystals that are similar to the experimental findings. An electronic wave function was added. 70 Ry energy cutoff values at particular $k$-points were produced by the $18 \times 18 \times 18$ Monkhorst-Pack mesh in the Brillouin zone for gismondine $\left(\mathrm{Ca}_{2} \mathrm{Al}_{4-}\right.$ $\mathrm{Si}_{4} \mathrm{O}_{16} \cdot 9 \mathrm{H}_{2} \mathrm{O}$ ) structures. The energy convergence threshold between two successive steps was maintained at $10-6 \mathrm{eV}$, and the maximal Hellmann-Feynman force acting on each atom was kept to a minimum [77] less than $0.001 \mathrm{eV}$. Finally, the optimized structures were utilized to compute the electronic and density of states' properties calculated in the present study.

4.1. Electronic and PDOS Structure Calculation. In Figure 9, the structural optimization of gismondine $\left(\mathrm{Ca}_{2} \mathrm{Al}_{4} \mathrm{Si}_{4} \mathrm{O}_{16}\right.$. $9 \mathrm{H} 2 \mathrm{O}$ ) structures was carried out in the first stage under the lowest condition of total energy and forces acting on atoms for the lattice constant, as well as the available experimental [78] and theoretical findings. The computed value of the lattice constant agrees well with observed values [78] and differs by less than $1 \%$ from other theoretical work [79]. The differences can be attributed to the differences in calculating methods.

To better comprehend the electronic characteristics, the density of states (DOS) and projected DOS (PDOS) are computed, since they may explain the cause for bandgap modulation and the gap of gismondine $\left(\mathrm{Ca}_{2} \mathrm{Al}_{4} \mathrm{Si}_{4} \mathrm{O}_{16}\right.$. $9 \mathrm{H}_{2} \mathrm{O}$ ) structures was in $4.734 \mathrm{eV}$. The DOS and PDOS of $\mathrm{Ca}, \mathrm{Al}, \mathrm{Si}$, and $\mathrm{O}$ atoms are shown in Figure 9. The picture clearly shows that $s, p$, and $d$ are the most contributed energy in the formation of gismondine type zeolite; the $\mathrm{Ca}$ and $\mathrm{Al} \mathrm{d}$ orbital is the strong peak at Fermi level just above the conduction band maxima (CBM) in the range 0 to $-8 \mathrm{eV}$, as well as some density contribution near the valence band minima (VBM) in the region $4 \mathrm{eV}$ to $18 \mathrm{eV}$. This additional 

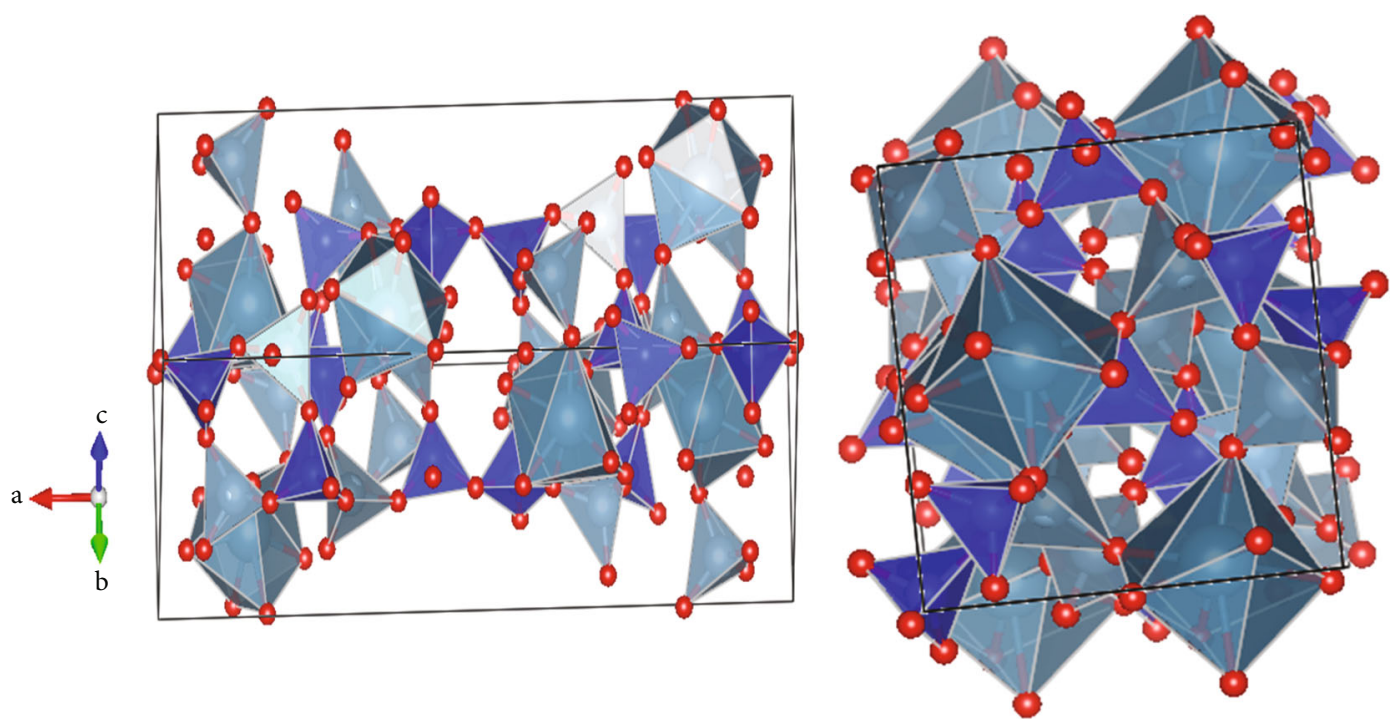

Figure 8: The crystal structure of gismondine $\left(\mathrm{Ca}_{2} \mathrm{Al}_{4} \mathrm{Si}_{4} \mathrm{O}_{16} \cdot 9 \mathrm{H}_{2} \mathrm{O}\right)$.

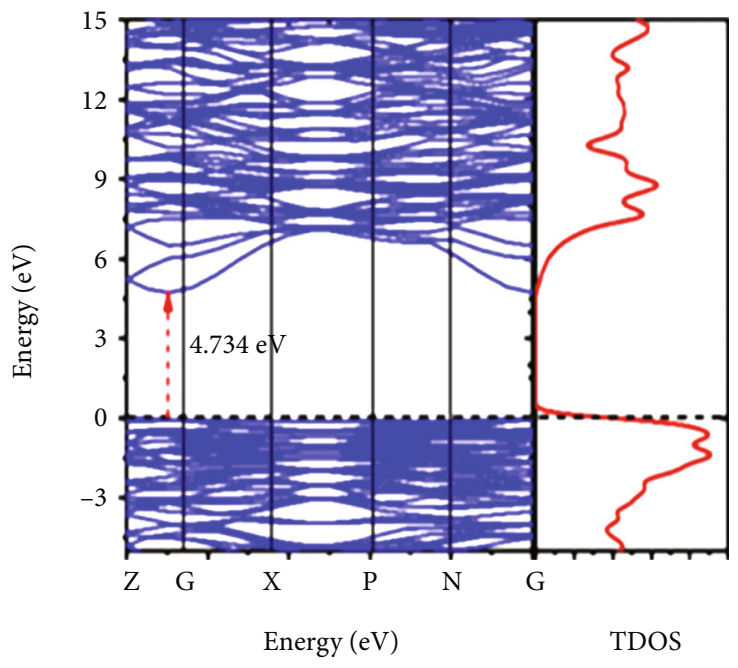

(a)

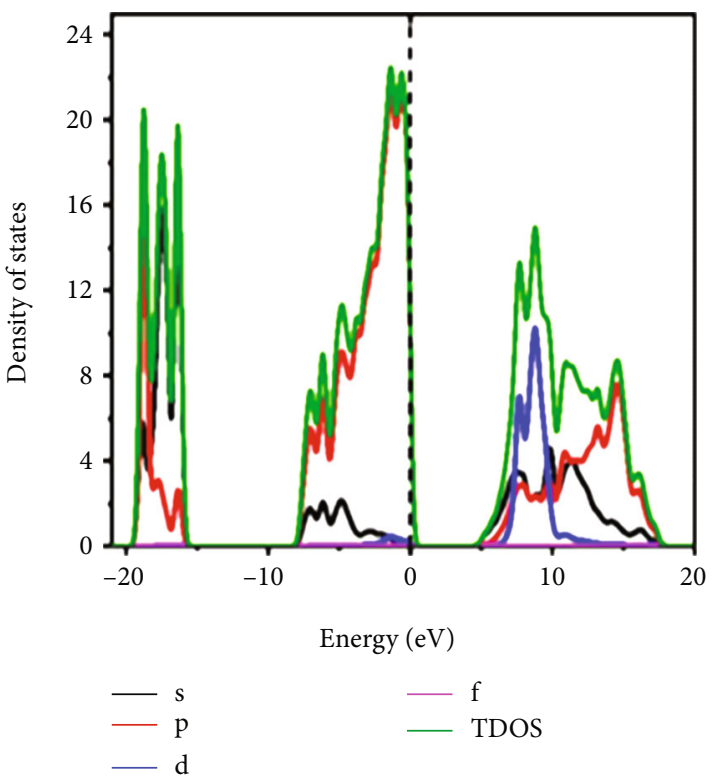

(b)

FIgure 9: Band structures. (a) Electronic band structure and TDOS. (b) Projection density of states (PDOS) plot of gismondine $\left(\mathrm{Ca}_{2} \mathrm{Al}_{4} \mathrm{Si}_{4} \mathrm{O}_{16} \cdot 9 \mathrm{H}_{2} \mathrm{O}\right)$.

peak results from the contribution of $2 \mathrm{~s}$ and $2 \mathrm{p}$ orbital electrons in $\mathrm{Ca}$ and $\mathrm{Al}$ at both CBM and VBM. The $3 \mathrm{~d}$ orbit electron of $\mathrm{Si}$ and $\mathrm{O}$ has a little effect on the VBM between -11 and $-20 \mathrm{eV}$.

\section{Conclusion}

Increasing global awareness towards environmental issues acts as a driving force towards the recovery of value-added minerals from waste materials. The present paper focuses on the green synthesis of zeolites using incense stick ash waste. The synthesis of zeolites from the household waste incense stick ash is justified as the waste, whose disposal causes environmental problem especially in water, is utilized. The obtained Ca-rich zeolites were cuboidal in shape with size between 200 and $700 \mathrm{~nm}$ as revealed by TEM analysis. The zeolites were microporous and crystalline in nature suitable as an adsorbent material for the remediation of contaminants present in water. The other analysis results such as FTIR, PSA, XRD, and XRF also confirmed the successful synthesis of zeolites from ISA. The present work effectively draws possibility to utilize the ISA for the synthesis of $\mathrm{Ca}$ rich zeolites. Besides, theoretical calculations were also established for the band structure and density of states' 
characteristics of gismondine $\left(\mathrm{Ca}_{2} \mathrm{~A}_{14} \mathrm{Si}_{4} \mathrm{O}_{16} \cdot 9 \mathrm{H}_{2} \mathrm{O}\right)$ structures. The structural optimization was carried out in the first stage under the lowest condition of total energy and forces acting on atoms for the lattice constant. The bandgap of gismondine structures was in $4.734 \mathrm{eV}$. The quality of the fabricated zeolite product strongly relies on environmental treatments and the strength of the raw materials [80]. The ISA-based zeolites have the potential to remediate both heavy and alkali metals from wastewater. Hence, the ISAbased synthesis of zeolites is an efficient, low-cost, and green chemistry-based method that opens a new possibility in the field of material science and catalysis.

\section{Data Availability}

The data sets used and analyzed during the current study are available within the article only.

\section{Conflicts of Interest}

The authors declare that there is no conflict of interest.

\section{Authors' Contributions}

Virendra Kumar Yadav (V.K.Y.), G. Gnanamoorthy (G.G.), Nisha Choudhary (N.C.), Daoud Ali (D.A.), and Mohammed HA. Almarzoug (M.H.A.)Gokhlesh Kumar (G.K.) were responsible for conceptualization; V.K.Y., G.G., and N.C. were responsible for methodology; V.K.Y., D.A., and N.C. were responsible for software; V.K.Y., D.A., G.K., and N.C. were responsible for validation; V.K.Y., S.H.K., M.H.A., D.A., G.K., and N.C. were responsible for formal analysis; V.K.Y., G.G., and N.C. were responsible for investigation; V.K.Y., D.A., and N.C. were responsible for resources; G.K., D.A., M.H.A., G.G., and N.C. were responsible for data curation; D.A., V.K.Y., G.K., G.G., and N.C. were responsible for writing-original draft preparation; D.A. and V.K.Y. were responsible for writing-review and editing; V.K.Y., M.H.A., G.G., and N.C. were responsible for visualization; V.K.Y. and N.C. were responsible for supervision; V.K.Y., D.A., and N.C. were responsible for project administration; D.A. was responsible for funding acquisition. Reviewing, editing, and computational approach simulated by G.K.I. and S.H.K. and Mitesh B. Solanki. All authors have read and agree to the published version of the manuscript.

\section{Acknowledgments}

This work was funded by Researchers Supporting Project number RSP-2021/165, King Saud University, Riyadh, Saudi Arabia.

\section{References}

[1] J. Grand, H. Awala, and S. Mintova, "Mechanism of zeolites crystal growth: new findings and open questions," CrystEngComm, vol. 18, no. 5, pp. 650-664, 2016.

[2] S. Prodinger and M. A. Derewinski, "Recent progress to understand and improve zeolite stability in the aqueous medium," Petroleum Chemistry, vol. 60, no. 4, pp. 420-436, 2020.
[3] S. Guida, C. Potter, B. Jefferson, and A. Soares, "Preparation and evaluation of zeolites for ammonium removal from municipal wastewater through ion exchange process," Scientific Reports, vol. 10, no. 1, article 12426, 2020.

[4] W. Bao, L. Liu, H. Zou et al., "Removal of $\mathrm{Cu}^{2+}$ from aqueous solutions using Na-a zeolite from oil shale ash," Chinese Journal of Chemical Engineering, vol. 21, no. 9, pp. 974-982, 2013.

[5] J. Přech, P. Pizarro, D. P. Serrano, and J. Čejka, "From 3D to 2D zeolite catalytic materials," Chemical Society Reviews, vol. 47, pp. 8263-8306, 2018.

[6] S. Krause, N. Hosono, and S. Kitagawa, "Chemistry of soft porous crystals: structural dynamics and gas adsorption properties," Angewandte Chemie International Edition, vol. 59, pp. 15325-15341, 2020.

[7] N. Jiang, R. Shang, S. G. J. Heijman, and L. C. Rietveld, "Highsilica zeolites for adsorption of organic micro-pollutants in water treatment: a review," Water Research, vol. 144, pp. 145-161, 2018.

[8] K. Mlekodaj, J. E. Olszowka, V. Tokarova et al., "Effect of alkali-free synthesis and post-synthetic treatment on acid sites in beta zeolites," Molecules, vol. 25, no. 15, p. 3434, 2020.

[9] P. J. Reeve and H. J. Fallowfield, "Natural and surfactant modified zeolites: a review of their applications for water remediation with a focus on surfactant desorption and toxicity towards microorganisms," Journal of Environmental Management, vol. 205, pp. 253-261, 2018.

[10] C. Belviso, "Zeolite for potential toxic metal uptake from contaminated soil: a brief review," Processes, vol. 8, no. 7, p. 820, 2020.

[11] Y. Li, L. Li, and J. Yu, "Applications of zeolites in sustainable chemistry," Chem, vol. 3, pp. 928-949, 2017.

[12] S. Sharma and A. Bhattacharya, "Drinking water contamination and treatment techniques," Applied Water Science, vol. 7, pp. 1043-1067, 2017.

[13] J. Byun, H. A. Patel, D. Thirion, and C. T. Yavuz, "Chargespecific size-dependent separation of water-soluble organic molecules by fluorinated nanoporous networks," Nature Communications, vol. 7, article 13377, 2016.

[14] A. Georgiadis, N. Charisiou, and M. Goula, "Removal of hydrogen sulfide from various industrial gases: a review of the most promising adsorbing materials," Catalysts, vol. 10, p. 36, 2020.

[15] W. Zou, H. Bai, L. Zhao, K. Li, and R. Han, "Characterization and properties of zeolite as adsorbent for removal of uranium(VI) from solution in fixed bed column," Journal of Radioanalytical and Nuclear Chemistry, vol. 288, pp. 779788, 2011.

[16] N. Elboughdiri, "The use of natural zeolite to remove heavy metals $\mathrm{Cu}$ (II), $\mathrm{Pb}$ (II) and Cd (II), from industrial wastewater," Cogent Engineering, vol. 7, no. 1, p. 13, 2020.

[17] S. A. A. Nakhli, M. Delkash, B. E. Bakhshayesh, and H. Kazemian, "Application of zeolites for sustainable agriculture: a review on water and nutrient retention," Water, Air, \& Soil Pollution, vol. 228, no. 12, p. 464, 2017.

[18] H. Deng and Y. Ge, "Formation of NaP zeolite from fused fly ash for the removal of $\mathrm{Cu}$ (ii) by an improved hydrothermal method," RSC Advances, vol. 5, pp. 9180-9188, 2015.

[19] D. Wu, B. Zhang, C. Li, Z. Zhang, and H. Kong, "Simultaneous removal of ammonium and phosphate by zeolite synthesized from fly ash as influenced by salt treatment," Journal of Colloid and Interface Science, vol. 304, pp. 300-306, 2006. 
[20] Ž. Z. Tasić, G. D. Bogdanović, and M. M. Antonijević, “Application of natural zeolite in wastewater treatment: a review," Journal of Mining and Metallurgy A: Mining, vol. 55, no. 1, pp. 67-79, 2019.

[21] B. de Gennaro, P. Aprea, B. Liguori, B. Galzerano, A. Peluso, and D. Caputo, "Zeolite-rich composite materials for environmental remediation: arsenic removal from water," Applied Sciences, vol. 10, no. 19, p. 6939, 2020.

[22] H. Tang, X. Xu, B. Wang, C. Lv, and D. Shi, "Removal of ammonium from swine wastewater using synthesized zeolite from fly ash," Sustainability, vol. 12, p. 15, 2020.

[23] P. A. Dinis, M. M. S. Cabral Pinto, E. Garzanti, and F. T. Rocha, "Detrital record of the denudation of volcanic islands under sub-tropical climate (Cape Verde)," Geochemistry, vol. 79, pp. 235-246, 2019.

[24] M. M. S. Cabral-Pinto, M. Inácio, O. Neves et al., "Human health risk assessment due to agricultural activities and crop consumption in the surroundings of an industrial area," Exposure and Health, vol. 12, pp. 629-640, 2019.

[25] M. M. S. Cabral Pinto, P. A. Dinis, M. M. V. G. Silva, and E. A. Ferreira da Silva, "Sediment generation on a volcanic island with arid tropical climate: a perspective based on geochemical maps of topsoils and stream sediments from Santiago Island, Cape Verde," Applied Geochemistry, vol. 75, pp. 114-124, 2016.

[26] M. M. S. C. Pinto, E. Silva, M. Silva, P. Melo-Gonçalves, and C. Candeias, "Environmental risk assessment based on highresolution spatial maps of potentially toxic elements sampled on stream sediments of Santiago, Cape Verde," Geosciences, vol. 4, no. 4, pp. 297-315, 2014.

[27] M. Król, "Natural vs. synthetic zeolites," Crystals, vol. 10, no. 7, p. $622,2020$.

[28] W. Franus, M. Wdowin, and M. Franus, "Synthesis and characterization of zeolites prepared from industrial fly ash," Environmental Monitoring and Assessment, vol. 186, no. 9, pp. 5721-5729, 2014.

[29] M. Gougazeh and J. C. Buhl, "Synthesis and characterization of zeolite A by hydrothermal transformation of natural Jordanian kaolin," Journal of the Association of Arab Universities for Basic and Applied Sciences, vol. 15, no. 1, pp. 35-42, 2014.

[30] A. Dussan, J. A. Calderón, and H. P. Quiroz, "Zeolites derived from natural minerals: solid rock and volcanic ash," Materials Today, vol. 34, pp. 148-149, 2020.

[31] N. Shiota, M. Togo, and A. Nakahira, "Synthesis of zeolites from volcanic ash and its evaluation," Journal of the Japan Society of Powder and Powder Metallurgy, vol. 64, pp. 601605, 2017.

[32] M. Ç. Karakaya, N. Karakaya, and F. Yavuz, "Geology and conditions of formation of the zeolite-bearing deposits southeast of Ankara (Central Turkey)," Clays and Clay Minerals, vol. 63, pp. 85-109, 2015.

[33] P. Pereira, B. Ferreira, N. Oliveira et al., "Synthesis of zeolite a from metakaolin and its application in the adsorption of cationic dyes," Applied Sciences, vol. 8, no. 4, p. 608, 2018.

[34] X.-Y. Li, Y. Jiang, X.-Q. Liu, L.-Y. Shi, D.-Y. Zhang, and L.B. Sun, "Direct synthesis of zeolites from a natural clay, attapulgite," ACS Sustainable Chemistry \& Engineering, vol. 5, no. 7, pp. 6124-6130, 2017.

[35] V. K. Yadav, R. Suriyaprabha, G. K. Inwati et al., "A noble and economical method for the synthesis of low cost zeolites from coal fly ash waste," Advances in Materials and Processing Technologies, vol. 6, pp. 1-19, 2021.

[36] C. Wang, J. Zhou, Y. Wang, M. Yang, Y. Li, and C. Meng, "Synthesis of zeolite X from low-grade bauxite," Journal of Chemical Technology \& Biotechnology, vol. 88, pp. 13501357, 2013.

[37] V. K. Yadav, N. Choudhary, V. Tirth et al., "A short review on the utilization of incense sticks ash as an emerging and overlooked material for the synthesis of zeolites," Crystals, vol. 11, no. 10, p. 1255, 2021.

[38] V. K. Yadav, K. K. Yadav, V. Tirth et al., "Extraction of valueadded minerals from various Agricultural, Industrial and Domestic Wastes," Industrial and Domestic Wastes Materials, vol. 14, no. 21, p. 6333, 2021.

[39] V. K. Yadav, G. Gnanamoorthy, M. M. S. Cabral-Pinto et al., "Variations and similarities in structural, chemical, and elemental properties on the ashes derived from the coal due to their combustion in open and controlled manner," Environmental Science and Pollution Research, vol. 28, pp. 3260932625, 2021.

[40] T.-C. Lin, G. Krishnaswamy, and D. S. Chi, "Incense smoke: clinical, structural and molecular effects on airway disease," Clinical and Molecular Allergy, vol. 6, no. 1, pp. 3-3, 2008.

[41] M. Waghmode, A. Gunjal, N. Nawani, and N. Patil, "Management of floral waste by conversion to value-added products and their other applications," Waste and Biomass Valorization, vol. 9, pp. 33-43, 2018.

[42] C.-R. Yang, T.-C. Lin, and F.-H. Chang, "Correlation between calcium carbonate content and emission characteristics of incense," Journal of the Air \& Waste Management Association, vol. 56, no. 12, pp. 1726-1732, 2006.

[43] V. K. Yadav, B. Singh, and N. Choudhary, "Characterization of Indian incense stick powders for their physical, chemical and mineralogical properties," World Journal of Environmental Biosciences, vol. 9, pp. 39-43, 2020.

[44] V. K. Yadav, K. K. Yadav, G. Gnanamoorthy et al., "A novel synthesis and characterization of polyhedral shaped amorphous iron oxide nanoparticles from incense sticks ash waste," Environmental Technology \& Innovation, vol. 20, article 101089, 2020.

[45] X. Ren, R. Qu, S. Liu et al., "Synthesis of zeolites from coal fly ash for removal of harmful gaseous pollutants: a review," Aerosol and Air Quality Research, vol. 20, pp. 1127-1144, 2020.

[46] N. Koshy, D. Singh, B. Jha, S. Kadali, and J. Patil, "Characterization of $\mathrm{Na}$ and $\mathrm{Ca}$ zeolites synthesized by various hydrothermal treatments of fly ash," Advances in Civil Engineering Materials, vol. 4, pp. 131-143, 2015.

[47] N. Tangboriboon, S. Wongkasemjit, R. Kunanuruksapong, and A. Sirivat, "An innovative synthesis of calcium zeolite type a catalysts from eggshells via the sol-gel process," Journal of Inorganic and Organometallic Polymers and Materials, vol. 21, pp. 50-60, 2011.

[48] R. A. Boulos, F. Zhang, E. S. Tjandra, A. D. Martin, D. Spagnoli, and C. L. Raston, "Spinning up the polymorphs of calcium carbonate," Scientific Reports, vol. 4, p. 3616, 2014.

[49] H. Isawi, "Using zeolite/polyvinyl alcohol/sodium alginate nanocomposite beads for removal of some heavy metals from wastewater," Arabian Journal of Chemistry, vol. 13, pp. 5691-5716, 2020.

[50] H. Smail, M. Rehan, K. Shareef, Z. Ramli, A.-S. Nizami, and J. Gardy, "Synthesis of uniform mesoporous zeolite ZSM-5 
catalyst for Friedel-Crafts acylation," ChemEngineering, vol. 3, p. $35,2019$.

[51] P. Innocenzi, "Infrared spectroscopy of sol-gel derived silicabased films: a spectra-microstructure overview," Journal of Non-Crystalline Solids, vol. 316, pp. 309-319, 2003.

[52] N. M. Musyoka, L. F. Petrik, G. Balfour, W. M. Gitari, and E. Hums, "Synthesis of hydroxy sodalite from coal fly ash using waste industrial brine solution," Journal of Environmental Science and Health, Part A, vol. 46, pp. 1699-1707, 2011.

[53] W. Mozgawa, "The relation between structure and vibrational spectra of zeolites," Journal of Molecular Structure, vol. 596, pp. 129-137, 2001.

[54] M. Chigondo, U. Guyo, M. Shumba et al., "Synthesis and characterisation of zeolites from coal fly ash (CFA)," Synthesis, vol. 3, pp. 714-718, 2013.

[55] A. Fernández-Jiménez and A. Palomo, "Mid-infrared spectroscopic studies of alkali-activated fly ash structure," Microporous and Mesoporous Materials, vol. 86, pp. 207-214, 2005.

[56] M. Y. A. Mollah, S. Promreuk, R. Schennach, D. L. Cocke, and R. Güler, "Cristobalite formation from thermal treatment of Texas lignite fly ash,” Fuel, vol. 78, pp. 1277-1282, 1999.

[57] M. Rokita, W. Mozgawa, and M. Handke, "The influence of $\mathrm{Na}^{+}$and $\mathrm{Ca}^{2+}$ ions on the $\mathrm{SiO}_{2}-\mathrm{AlPO}_{4}$ materials structure IR and Raman studies," Journal of Molecular Structure, vol. 596, pp. 171-178, 2001.

[58] N. Kantiranis, A. Filippidis, T. Mouhtaris et al., "EPI-type zeolite synthesis from Greek sulphocalcic fly ashes promoted by $\mathrm{H}_{2} \mathrm{O}_{2}$ solutions," Fuel, vol. 85, pp. 360-366, 2006.

[59] G. K. Inwati, P. Kumar, W. D. Roos, H. C. Swart, and M. Singh, "UV-irradiation effects on tuning LSPR of Cu/Ag nanoclusters in ion exchanged glass matrix and its thermodynamic behaviour," Journal of Alloys and Compounds, vol. 823, article 153820, 2020.

[60] S. Mourdikoudis, R. M. Pallares, and N. T. K. Thanh, "Characterization techniques for nanoparticles: comparison and complementarity upon studying nanoparticle properties," Nanoscale, vol. 10, pp. 12871-12934, 2018.

[61] V. K. Yadav, D. Ali, S. H. Khan et al., "Synthesis and characterization of amorphous iron oxide nanoparticles by the sonochemical method and their application for the remediation of heavy metals from wastewater," Nanomaterials, vol. 10, p. 1551, 2020.

[62] D. Czarna-Juszkiewicz, P. Kunecki, R. Panek, J. Madej, and M. Wdowin, "Impact of fly ash fractionation on the zeolitization process," Materials, vol. 13, no. 5, article 1035, 2020.

[63] M. A. Klunk, S. B. Schröpfer, S. Dasgupta et al., "Synthesis and characterization of mordenite zeolite from metakaolin and rice husk ash as a source of aluminium and silicon," Chemical Papers, vol. 74, pp. 2481-2489, 2020.

[64] F. Stoppa, F. Scordari, E. Mesto, V. Sharygin, and G. Bortolozzi, "Calcium-aluminum-silicate-hydrate "cement" phases and rare Ca-zeolite association at Colle Fabbri, Central Italy," Central European Journal of Geosciences, vol. 2, pp. 175$187,2010$.

[65] G. Ferretti, G. Galamini, V. Medoro, M. Coltorti, D. Di Giuseppe, and B. Faccini, "Impact of sequential treatments with natural and $\mathrm{Na}$-exchanged chabazite zeolite-rich tuff on pigslurry chemical composition," Water, vol. 12, p. 20, 2020.

[66] T. Ennaert, J. Van Aelst, J. Dijkmans et al., "Potential and challenges of zeolite chemistry in the catalytic conversion of biomass," Chemical Society Reviews, vol. 45, pp. 584611, 2016.

[67] G. Abbas, M. Saqib, J. Akhtar, G. Murtaza, M. Shahid, and A. Hussain, "Relationship between rhizosphere acidification and phytoremediation in two acacia species," Journal of Soils and Sediments, vol. 16, pp. 1392-1399, 2016.

[68] K. Li and D. Xue, "Estimation of electronegativity values of elements in different valence states," The Journal of Physical Chemistry A, vol. 110, no. 39, pp. 11332-11337, 2006.

[69] X. Zhao, F. Gu, Y. Wang, Z. Peng, and J. Liu, "Surface electronegativity as an activity descriptor to screen oxygen evolution reaction catalysts of $\mathrm{Li}-\mathrm{O}_{2}$ battery," ACS Applied Materials \& Interfaces, vol. 12, pp. 27166-27175, 2020.

[70] V. Pandey, M. Ray, and V. Kumar, "Assessment of waterquality parameters of groundwater contaminated by fly ash leachate near Koradi Thermal Power Plant, Nagpur," Environmental Science and Pollution Research, vol. 27, pp. 2742227434, 2020.

[71] S. Rajendran, G. K. Inwati, V. K. Yadav et al., "Enriched catalytic activity of $\mathrm{TiO}_{2}$ nanoparticles supported by activated carbon for noxious pollutant elimination," Nanomaterials, vol. 11, no. 11, p. 2808, 2021.

[72] M. B. Solanki, P. Patel, S. Shinde, B. B. Parekh, and M. Joshi, "Growth and characterization of lithium chloride doped KDP crystals: a DFT and experimental approach," Ferroelectrics, vol. 571, no. 1, pp. 1-25, 2021.

[73] P. Giannozzi, S. Baroni, N. Bonini et al., "QUANTUM ESPRESSO: a modular and open-source software project for quantum simulations of materials," Journal of Physics: Condensed Matter, vol. 21, no. 39, article 395502, 2009.

[74] J. P. Perdew, K. Burke, and M. Ernzerhof, "Generalized gradient approximation made simple," Physical Review Letters, vol. 77, no. 18, pp. 3865-3868, 1996.

[75] G. Petretto, S. Dwaraknath, H. P. C. Miranda et al., "Highthroughput density-functional perturbation theory phonons for inorganic materials," Scientific Data, vol. 5, no. 1, article 180065, 2018.

[76] W. Kohn and L. J. Sham, "Self-consistent equations including exchange and correlation effects," Physical Review, vol. 140, no. 4A, pp. A1133-A1138, 1965.

[77] M. Cococcioni, F. Mauri, G. Ceder, and N. Marzari, "Electronic-enthalpy functional for finite systems under pressure," Physical Review Letters, vol. 94, no. 14, article 145501, 2005.

[78] M. C. Payne, M. Hytha, I. Štich, J. D. Gale, and K. Terakura, "First principles calculation of the free energy barrier for the reaction of methanol in a zeolite catalyst," Microporous and Mesoporous Materials, vol. 48, no. 1-3, pp. 375-381, 2001.

[79] S. Yang, M. Lach-hab, I. I. Vaisman, E. Blaisten-Barojas, X. Li, and V. L. Karen, "Framework-type determination for zeolite structures in the inorganic crystal structure database," Journal of Physical and Chemical Reference Data, vol. 39, no. 3, article 033102, 2010.

[80] A. Khaleque, M. M. Alam, M. Hoque et al., "Zeolite synthesis from low-cost materials and environmental applications: a review," Environmental Advances, vol. 2, article 100019, 2020. 